ESAIM: PROCEEDINGS AND SURVEYS, March 2015, Vol. 50, p. 21-39

Franck BOYER, Thierry GALLOUET, Raphaèle HERBIN and Florence HUBERT Editors

\title{
NUMERICAL SIMULATION OF TWO-PHASE MULTICOMPONENT FLOW WITH REACTIVE TRANSPORT IN POROUS MEDIA: APPLICATION TO GEOLOGICAL SEQUESTRATION OF $\mathrm{CO}_{2}{ }^{*}$
}

\author{
Etienne AHUSBORDE ${ }^{1}$, Michel KERN² and Viatcheslav VOSTRIKOV ${ }^{3}$
}

Dedicated to Amaia, for a long and happy life

\begin{abstract}
In this work, we consider two-phase multicomponent flow in heterogeneous porous media with chemical reactions. Equations governing the system are the mass conservation law for each species, together with Darcy's law and complementary equations such as the capillary pressure law. Coupling with chemistry occurs through reactions rates. These rates can either be given non-linear functions of concentrations in the case of kinetic chemical reactions or are unknown in the case of equilibrium chemical reactions (such as reactions in aqueous phase). In this latter case, each reaction gives rise to a mass action law, an algebraic relation that relates the activities of the implied species. The resulting system will couple partial differential equations with algebraic equations. The aim of this paper is to develop a numerical method for the simulation of this system. We consider a sequential approach that consists in splitting the initial problem into two sub-systems. The first subsystem is a two-phase two-component flow, while the second subsystem is devoted to a reactive transport problem. For the two-phase two-component flow part, we have used an already existing module of the open-source parallel multiphase flow simulator $\mathrm{DuMu}^{X}$. To solve the reactive transport problem, we have implemented a new module in the $\mathrm{DuMu}^{X}$ framework that solves a single phase multicomponent transport problem, and we have coupled it with a locally developed code for chemical equilibrium, called ChemEqLib, through a sequential iterative approach. Then, both modules have been coupled to propose a simple, but mathematically consistent, iterative method that handles two-phase flow with reactive transport. The approach is validated on a $2 \mathrm{D}$ example from the literature representative of a model for the long-term fate of sequestered $\mathrm{CO}_{2}$.
\end{abstract}

\section{INTRODUCTION}

Carbon Capture and Storage (CCS) is seen as one of the ways to mitigate the effects of global warming, and assessing the viability of geological storage must rely on numerical simulations, if only because of the long time scales involved. Several physical and geochemical trapping mechanisms must be combined to ensure a

* This research has been supported by the Conseil Régional d'Aquitaine, and the CEA-INSTN. Their support is gratefully acknowledged.

${ }^{1}$ LMA Pau UMR 5142, Bâtiment IPRA - UPPA, Avenue de l'Université - BP 1155, 64013 Pau Cedex

2 INRIA, CRI Paris-Rocquencourt, BP 105, 78153 Le Chesnay Cedex \& Maison de la Simulation, Digiteo Labs, CEA Saclay, 91191 Gif-sur-Yvette Cedex

${ }^{3}$ LMA Pau UMR 5142, Bâtiment IPRA - UPPA, Avenue de l'Université - BP 1155, 64013 Pau Cedex \& Maison de la Simulation, Digiteo Labs, CEA Saclay, 91191 Gif-sur-Yvette Cedex

(C) EDP Sciences, SMAI 2015 
high containment rate, and geochemical chemical trapping becomes increasingly important over longer time scales [18]: carbon dissolution in water occurs over hundreds of years, and formation of carbonate minerals over millions of years, see [21].

The physical description of $\mathrm{CO}_{2}$ geological storage rests on underground flow of water and $\mathrm{CO}_{2}$, both in aqueous and gaseous phases, as well as chemical interactions between them and the surrounding rock matrix, and other dissolved chemical species. From the numerical point of view, this task requires the solution of a large coupled system of partial differential equations (describing two-phase compositional flow), together with algebraic or ordinary differential equations modelling chemical reactions. This paper presents a numerical method to simulate such a system .

Both (compositional) multiphase flow and geochemical transport have been the subject of numerous studies, some of which are recalled below. More recently, codes targeting coupled two-phase flow and reactive transport have appeared. Several such codes are described in the book edited by Zhang et al. [31], and two more recent references are the papers by Saaltink et al. [25] and Fan et al. [12].

As usual for coupled problems, the coupling between flow, transport and chemistry can be treated in one of two ways. In a fully coupled procedure, one nonlinear system gathering all equations is solved at each time step. This is the approach adopted in [12] and also in [25]. But, even though both works do solve the fully coupled problem, they do not couple two different codes. Rather, they add chemical equations to an existing, sophisticated two-phase flow solver. In the case of [12], the chemical equations are solved together with the conservation laws for flow and transport. In the case of [25], however, the solution of the chemical problem is pre-computed for some number of reference conditions (they are shown to depend only on gas pressure), and then polynomial interpolation is used within the solution procedure, leading to a large reduction in computing time.

Given the complexity of the chemistry codes, it may not be surprising that most studies using such type of codes have instead focused on the sequential solution approach, where flow and reactive transport (or possibly, flow, transport and chemistry) are solved sequentially at each time step, possibly within an iterative loop. This is in particular the case for the codes described in [31], such as [15], [16], [27] and [29]. No comparative study exists yet to quantify the accuracy loss for this approach, but its gain in implementation and saving in computing time are fairly obvious. This is the approach we have chosen to follow in this paper.

An outline for the rest of the paper is as follows: we detail the physical model for two-phase, multicomponent flow, with reactive transport in section 1 . The sequential strategy is described in section 2 , both in a general setting and as it applies to the specific case of $\mathrm{CO}_{2}$ sequestration. Section 3 contains a description of the simulator, as well as its application to a test case taken from [25].

\section{MAThematical AND PHYSiCAL MODEL}

\subsection{Chemical equations}

We consider a set of $N_{s}$ chemical species $\left(Y_{j}\right)_{j=1 \ldots N_{s}}$ linked by $N_{r}$ equilibrium reactions:

$$
\sum_{j=1}^{N_{s}} \mathbb{S}_{i j} Y_{j} \leftrightarrows 0, \quad i=1, \ldots, N_{r} \Longleftrightarrow \mathbb{S} Y \leftrightarrows 0
$$

where $\mathbb{S} \in \mathbb{R}^{N_{s} \times N_{r}}$ is the stoichiometric matrix. Each reaction gives rise to a mass action law that links the activities of the species. In this work, we assume that all aqueous species have ideal activity (that is, activity equals concentration), whereas solid species have (by convention) their activity equal to 1 . When written in logarithmic form, the mass action law becomes linear and takes the form

$$
\mathbb{S} \log a=\log K
$$


where $a$ is a vector of activities and fugacities of all chemical species, $K$ is a vector of equilibrium constants, and we have used the convention that $\log a$ is the vector with components $\log a_{i}$ for any vector $a$ with positive components $a_{i}$.

We follow the Morel formalism [20], and split the set of all chemical species into primary and secondary species. If we assume that the stoichiometric matrix has full rank (there are no redundant reactions), it can then be transformed to the form:

$$
\mathbb{S}=\left(\begin{array}{ll}
-I & \tilde{\mathbb{S}}
\end{array}\right)
$$

so that each chemical reaction expresses the formation of a single secondary species from the set of primary species.

In addition to the mass action law, each primary species gives rise to a conservation equation that expresses how its given total concentration is distributed among the species itself and the secondary species. The mass conservation law is written as follows:

$$
c_{p}+\tilde{\mathbb{S}}^{T} c_{s}=T,
$$

where $c_{p}$ and $c_{s}$ are the vectors of concentrations of primary and secondary species and the total concentration $T$ is known (see next section).

Solving the chemical equilibrium problem consists in solving the non-linear system that couples equations (1) and (3).

\subsection{Mathematical model for two-phase multicomponent flow with reactive transport}

In the sequel, the index $\alpha \in\{l, g, s\}$ ( $l$ for liquid, $g$ for gas and $s$ for solid) refers to the phase, while the superscript $i$ refers to the species. To specify which species belongs to which phase, we define the phase - species correspondence by setting $\alpha_{i}$ to the index of the phase that contains species $i$ (see an example in section 2.2).

For each species, in its phase, we consider the mass balance equation (see for instance [17]):

$$
\frac{\partial}{\partial t}\left(\theta_{\alpha_{i}} c^{i}\right)-\nabla \cdot\left(\theta_{\alpha_{i}} D_{\alpha_{i}} \nabla c^{i}\right)+\nabla \cdot\left(c^{i} \overrightarrow{q_{\alpha_{i}}}\right)=\sum_{j} \mathbb{S}_{j i} r_{j}, \quad i=1 \ldots N_{s},
$$

where $\theta_{\alpha}$ [-] denotes the volumetric content of phase $\alpha\left(\theta_{\alpha}=\phi S_{\alpha}, \phi[-]\right.$ being the porosity of the medium and $S_{\alpha}[-]$ the saturation of phase $\alpha$ if $\alpha \in\{l, g$,$\left.\} and \theta_{s}=1\right), c^{i}\left[\mathrm{~kg} \cdot \mathrm{m}^{-3}\right]$ is the mass concentration of species $i$ (in phase $\alpha_{i}$ ), $D_{\alpha}\left[\mathrm{m}^{2} . \mathrm{s}^{-1}\right]$ denotes the diffusivity of phase $\alpha, \overrightarrow{q_{\alpha}}\left[\mathrm{m}_{\mathrm{s}} \mathrm{s}^{-1}\right]$ is the Darcy velocity of phase $\alpha, r_{j}$ $\left[\mathrm{kg} \cdot \mathrm{m}^{-3} \cdot \mathrm{s}^{-1}\right]$ is the rate of reaction $j$ and $\mathbb{S}_{j i}[-]$ is the stoichiometric coefficient of species $i$ in reaction $j$. Note that we have made the simplifying (but essential for the decoupling procedure) assumption that the diffusion coefficient is independant of the chemical species $i$.

The Darcy velocity of phase $\alpha$ is expressed as follows:

$$
\overrightarrow{q_{\alpha}}=-\frac{k_{r \alpha}}{\mu_{\alpha}} \mathbb{K}\left(\nabla P_{\alpha}-\rho_{\alpha} \vec{g}\right)
$$

where $k_{r \alpha}\left(S_{l}\right)$ [-] denotes the relative permeability of phase $\alpha, \mu_{\alpha}$ [Pa.s] is the dynamic viscosity of phase $\alpha, \mathbb{K}$ $\left[\mathrm{m}^{2}\right]$ is the absolute permeability tensor, $P_{\alpha}[\mathrm{Pa}]$ is the pressure of phase $\alpha, \rho_{\alpha}\left[\mathrm{kg} \cdot \mathrm{m}^{-3}\right]$ is density of phase $\alpha$ and $\vec{g}\left[\mathrm{~m} \cdot \mathrm{s}^{-2}\right]$ is the gravitational acceleration.

The phase pressures are connected by the capillary pressure law:

$$
P_{c}\left(S_{l}\right)=P_{g}-P_{l}
$$

To simplify notation, we introduce the diffusion-advection operator:

$$
L_{\alpha}(c)=-\nabla \cdot\left(\theta_{\alpha} D_{\alpha} \nabla c\right)+\nabla \cdot\left(c \overrightarrow{q_{\alpha}}\right)
$$


We add that, since the mobile phase is immobile, $D_{s}=0$ and $\overrightarrow{q_{s}}=\overrightarrow{0}$, so that $L_{s}()=$.0 .

In this work we assume that all reactions are at equilibrium, that is that the reaction rates are much faster than the rate implied by flow and transport. This assumption is certainly valid for reactions in the aqueous phase, or for the dissolution of gaseous $\mathrm{CO}_{2}$, but may be less justified for reactions involving minerals. Then, the reaction rates $r_{j}$ are unknown. They can be eliminated by multiplying equation (4) by a $\left(N_{s}-N_{r}\right) \times N_{r}$ component matrix $U$ such that $U \mathbb{S}^{T}=0$. This matrix exists because of the full rank assumption on $\mathbb{S}$.

When $\mathbb{S}$ is put in the special form (2), the component matrix $U$ is simply $U=\left(\begin{array}{ll}\tilde{S}^{T} & I\end{array}\right)$. In general, the computation of $U$ can be performed in different ways (see for instance [23]), the simplest being Gaussian elimination.

After multiplication by $U$, equation (4) becomes:

$$
\sum_{\alpha}\left(\frac{\partial}{\partial t}\left(\theta_{\alpha} C_{\alpha}^{k}\right)+L_{\alpha}\left(C_{\alpha}^{k}\right)\right)=0, \quad k=1, \ldots, N_{s}-N_{r}
$$

with

$$
C_{\alpha}^{k}=\sum_{i \text { st } \alpha_{i}=\alpha} U_{k i} c^{i}, \quad k=1, \ldots, N_{s}-N_{r}, \quad \alpha \in\{l, g, s\} .
$$

To complete this new reduced set of equations and obtain the same number of equations as there are unknowns, we add the $N_{r}$ mass actions laws defined by (1).

In the next section, we present our methodology to solve this new system composed of mass actions laws (1) and mass conservations laws (8).

\section{Solution METHODOLOGY}

In the literature, there are two main kinds of approaches for the numerical simulation of two-phase multicomponent flow with reactive transport in porous media. The first one is a fully-coupled approach that solves the full system of equations (1)-(8) simultaneously (see for instance [12]). The second one is a sequential approach (see for instance $[24,28]$ ) and is applicable if the following conditions are satisfied:

- Among the chemical species there exists one dominant species within each phase,

- Various phase states of the dominant species are in chemical equilibrium,

- The presence of other chemical species has no significant influence on the mass balance equations of the dominant species.

In this case, the solution process can be divided into two steps. In the first step, we consider a simplified two-phase two-component flow only governed by the dominant species and chemical reactions are neglected. In the second step, we consider a reactive transport problem for the other minor species using quantities computed at the first step.

In this work, we use this kind of sequential approach. In the rest of this section, we make our strategy precise.

\subsection{Sequential strategy}

The general idea of the sequential approach is to separate the system of equations into two subsystems, the first one devoted to a two-phase two-component flow and the second one devoted to the reactive transport problem. In the sequel, $c_{d}$ denotes the vector of concentrations of the dominant species in their potential various phase states while $c_{m}$ is the vector of concentrations of the minor species. The choice of dominant species is arbitrary, provided they satisfy the hypothesis outlined below, but in practice will be based on the expected properties of the system being studied. This is exemplified for a $\mathrm{H}_{2} \mathrm{O}_{-} \mathrm{CO}_{2}$ system in section 2.2.

We make the following assumptions:

- The dominant species must be part of the primary species. 
- We assume that the state equation for density depends only on the pressures and concentrations of dominant species.

\subsubsection{Two-phase two-component flow}

In this step we compute $c_{d}, \rho_{\alpha}, P_{\alpha}, S_{\alpha}$ and $\overrightarrow{q_{\alpha}}$. To do this, we consider equations (8) only for dominant species, the contribution from the minor ones being treated explicitly. To close the system, we add the mass action laws involving the dominant species and their potential various phase states. Note that we consider that interphase exchange relations, like Henry's or Raoult's law, are included in the mass action laws. In practice, this means that we are solving a two-phase, two-component flow, see section 3.1.1.

\subsubsection{Reactive transport}

Once the two-phase two-component flow has been computed, we can solve the reactive transport problem, given $c_{d}, \rho_{\alpha}, P_{\alpha}, S_{\alpha}$ and $\overrightarrow{q_{\alpha}}$, to obtain $c_{m}$. This problem consists of equations (8) for minor species and mass action laws defined by (1) that have not been taken into account in the two-phase two-component flow. Once $c_{m}$ is computed, the porosity can be updated thank to the relation:

$$
\phi=1-\theta_{\min },
$$

where $\theta_{\min }[-]$ is the mineral volumetric content. The mineral volumetric content is a function of the concentrations of the solid species and therefore depends on $c_{m}$. Moreover, the contribution of minor species in the equations (8) of the dominant species can be updated.

To summarize, our methodology for the coupling is illustrated in figure 1.

$$
\text { Two-Phase two-component flow }
$$

- Density of phase $\rho_{\alpha}$

- Velocity of phase $\overrightarrow{q_{\alpha}}$

- Saturation of phase $S_{\alpha}$

- Concentration of dominant species $c_{d}$

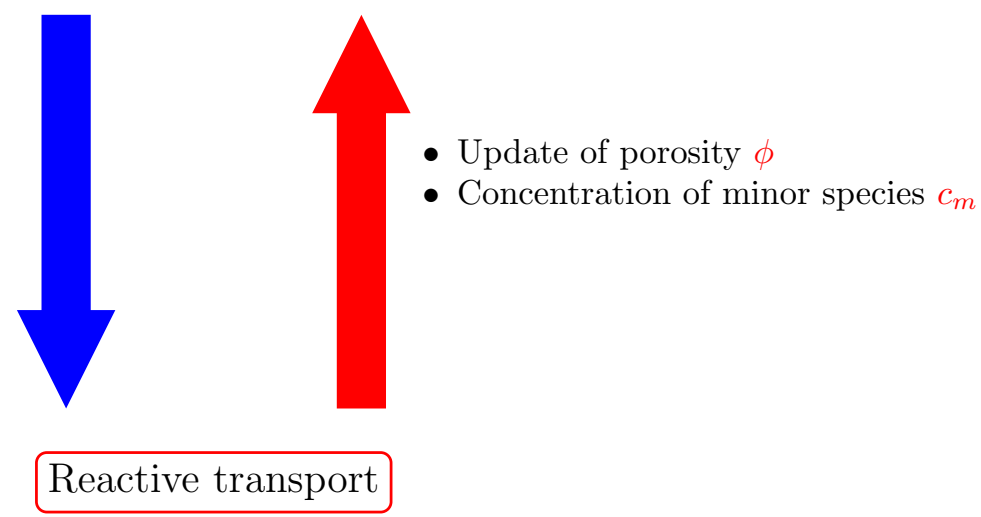

FIGURE 1. Coupling procedure between flow and reactive transport modules.

\subsection{Application to $\mathrm{CO}_{2}$ Storage}

The general strategy described above is illustrated by an application to a specific chemical system, typical of geological carbon storage studies, whose species are exhibited in table 1, and that will be used in the numerical example in section 3. 


\begin{tabular}{lcc}
\hline Liquid phase (l) & Gaseous phase (g) & Solid phase (s) \\
\hline $\mathrm{H}_{2} \mathrm{O}, \mathrm{CO}_{2(1)}, \mathrm{H}^{+}$, & $\mathrm{CO}_{2(\mathrm{~g})}$ & $\mathrm{CaCO}_{3}$ \\
$\mathrm{OH}^{-}, \mathrm{HCO}_{3}^{-}, \mathrm{Ca}^{2+}$ & & \\
\multicolumn{3}{c}{ TABLE 1. Chemical species. }
\end{tabular}

These species are divided into three phases and are involved in four chemical reactions, all assumed to be in equilibrium:

$$
\begin{aligned}
& \mathrm{R} 1: \mathrm{OH}^{-}+\mathrm{H}^{+} \rightleftharpoons \mathrm{H}_{2} \mathrm{O}, \\
& \mathrm{R} 2: \mathrm{HCO}_{3}{ }^{-}+\mathrm{H}^{+} \rightleftharpoons \mathrm{H}_{2} \mathrm{O}+\mathrm{CO}_{2(1)}, \\
& \text { R3 }: \mathrm{CO}_{2(\mathrm{~g})} \rightleftharpoons \mathrm{CO}_{2(1)}, \\
& \text { R4 }: \mathrm{CaCO}_{3}+2 \mathrm{H}^{+} \rightleftharpoons \mathrm{H}_{2} \mathrm{O}+\mathrm{CO}_{2(1)}+\mathrm{Ca}^{2+} .
\end{aligned}
$$

In this case $N_{s}=8, N_{r}=4$, and the phase -species correspondence is such that:

$$
\alpha_{\mathrm{H}_{2} \mathrm{O}}=\alpha_{\mathrm{CO}_{2(1)}}=\alpha_{\mathrm{OH}^{-}}=\alpha_{\mathrm{HCO}_{3}{ }^{-}}=\alpha_{\mathrm{Ca}^{2+}}=l, \quad \alpha_{\mathrm{CO}_{2(\mathrm{~g})}}=g, \quad \alpha_{\mathrm{CaCO}_{3}}=s .
$$

The system can be written in matrix-vector form as $\mathbb{S} Y \leftrightarrows 0$ with:

$$
\mathbb{S}=\left|\begin{array}{cccccccc}
-1 & 0 & 0 & 0 & 1 & 0 & -1 & 0 \\
0 & -1 & 0 & 0 & 1 & 1 & -1 & 0 \\
0 & 0 & -1 & 0 & 0 & 1 & 0 & 0 \\
0 & 0 & 0 & -1 & 1 & 1 & -2 & 1
\end{array}\right| \text { and } Y=\left|\begin{array}{c}
\mathrm{OH}^{-} \\
\mathrm{HCO}_{3}^{-} \\
\mathrm{CaCO}_{3} \\
\mathrm{CO}_{2(g)} \\
\mathrm{H}_{2} \mathrm{O} \\
\mathrm{CO}_{2(1)} \\
\mathrm{H}^{+} \\
\mathrm{Ca}^{2+}
\end{array}\right|
$$

Note that $\mathbb{S}$ is already in the special form pointed out in section 1.1, so that the component matrix $U$ can be read off directly from $\mathbb{S}$.

For each species in each phase, equation (4) writes:

$$
\begin{aligned}
& \mathrm{H}_{2} \mathrm{O} \quad: \frac{\partial}{\partial t}\left(\theta_{l} c^{\mathrm{H}_{2} \mathrm{O}}\right)+L_{l}\left(c^{\mathrm{H}_{2} \mathrm{O}}\right) \quad=r_{\mathrm{OH}^{-}}+r_{\mathrm{CaCO}_{3}}+r_{\mathrm{HCO}_{3}}{ }^{-}, \\
& \mathrm{CO}_{2(1)}: \frac{\partial}{\partial t}\left(\theta_{l} c^{\mathrm{CO}_{2(1)}}\right)+L_{l}\left(c^{\mathrm{CO}_{2(1)}}\right)=r_{\mathrm{HCO}_{3}}{ }^{-}+r_{\mathrm{CO}_{2(\mathrm{~g})}}+r_{\mathrm{CaCO}_{3}}, \\
& \mathrm{H}^{+} \quad: \frac{\partial}{\partial t}\left(\theta_{l} c^{\mathrm{H}^{+}}\right)+L_{l}\left(c^{\mathrm{H}^{+}}\right) \quad=-r_{\mathrm{OH}^{-}}-2 r_{\mathrm{CaCO}_{3}}-r_{\mathrm{HCO}_{3}}{ }^{-}, \\
& \mathrm{Ca}^{2+}: \frac{\partial}{\partial t}\left(\theta_{l} c^{\mathrm{Ca}^{2+}}\right)+L_{l}\left(c^{\mathrm{Ca}^{2+}}\right) \quad=r_{\mathrm{CaCO}_{3}}, \\
& \mathrm{HCO}_{3}{ }^{-}: \frac{\partial}{\partial t}\left(\theta_{l} c^{\mathrm{HCO}_{3}{ }^{-}}\right)+L_{l}\left(c^{\mathrm{HCO}_{3}}{ }^{-}\right)=-r_{\mathrm{HCO}_{3}}{ }^{-}, \\
& \mathrm{OH}^{-} \quad: \frac{\partial}{\partial t}\left(\theta_{l} c^{\mathrm{OH}^{-}}\right)+L_{l}\left(c^{\mathrm{OH}^{-}}\right)=-r_{\mathrm{OH}^{-}}, \\
& \mathrm{CO}_{2(\mathrm{~g})}: \frac{\partial}{\partial t}\left(\theta_{g} c^{\mathrm{CO}_{2(\mathrm{~g})}}\right)+L_{g}\left(c^{\left.\mathrm{CO}_{2(\mathrm{~g})}\right)}=-r_{\mathrm{CO}_{2(\mathrm{~g})}},\right. \\
& \mathrm{CaCO}_{3}: \frac{\partial}{\partial t} c^{\mathrm{CaCO}_{3}} \quad=-r_{\mathrm{CaCO}_{3}} \text {. }
\end{aligned}
$$


Multiplying this system by the matrix $U$ introduced previously is equivalent to performing linear combinations on its rows, so as to eliminate the equilibrium rates and reduce the number of equations from $N_{s}$ to $N_{s}-N_{r}$ :

$$
\begin{aligned}
& \frac{\partial}{\partial t}\left(\theta_{l} C_{l}^{\mathrm{H}_{2} \mathrm{O}}+C_{s}^{\mathrm{H}_{2} \mathrm{O}}\right)+L_{l}\left(C_{l}^{\mathrm{H}_{2} \mathrm{O}}\right)=0, \\
& \text { with } C_{l}^{\mathrm{H}_{2} \mathrm{O}}=c^{\mathrm{H}_{2} \mathrm{O}}+c^{\mathrm{OH}^{-}}+c^{\mathrm{HCO}_{3}^{-}} \text {and } C_{s}^{\mathrm{H}_{2} \mathrm{O}}=c^{\mathrm{CaCO}_{3}} \text {, } \\
& \frac{\partial}{\partial t}\left(\theta_{l} C_{l}^{\mathrm{CO}_{2(1)}}+\theta_{g} C_{g}^{\mathrm{CO}_{2(1)}}+C_{s}^{\mathrm{CO}_{2(1)}}\right)+L_{l}\left(C_{l}^{\mathrm{CO}_{2(1)}}\right)+L_{g}\left(C_{g}^{\mathrm{CO}_{2(1)}}\right)=0, \\
& \text { with } C_{l}^{\mathrm{CO}_{2(1)}}=c^{\mathrm{CO}_{2(1)}}+c^{\mathrm{HCO}_{3}{ }^{-}}, C_{g}^{\mathrm{CO}_{2(1)}}=c^{\mathrm{CO}_{2(\mathrm{~g})}} \text { and } C_{s}^{\mathrm{CO}_{2(1)}}=c^{\mathrm{CaCO}_{3}} \text {, } \\
& \frac{\partial}{\partial t}\left(\theta_{l} C_{l}^{\mathrm{H}^{+}}+C_{s}^{\mathrm{H}^{+}}\right)+L_{l}\left(C_{l}^{\mathrm{H}^{+}}\right)=0, \\
& \text { with } C_{l}^{\mathrm{H}^{+}}=c^{\mathrm{H}^{+}}-c^{\mathrm{OH}^{-}}-c^{\mathrm{HCO}_{3}^{-}} \text {and } C_{s}^{\mathrm{H}^{+}}=-2 c^{\mathrm{CaCO}_{3}} \text {, } \\
& \frac{\partial}{\partial t}\left(\theta_{l} C_{l}^{\mathrm{Ca}^{2+}}+C_{s}^{\mathrm{Ca}^{2+}}\right)+L_{l}\left(C_{\mathrm{Ca}^{2+}}\right)=0, \\
& \text { with } C_{l}^{\mathrm{Ca}^{2+}}=c^{\mathrm{Ca}^{2+}} \text { and } C_{s}^{\mathrm{Ca}^{2+}}=c^{\mathrm{CaCO}_{3}} \text {. }
\end{aligned}
$$

To recover a total number of equations equal to $N_{s}$, we add $N_{r}$ mass action laws:

$$
\begin{aligned}
\gamma\left(c^{\left.\mathrm{CO}_{2(\mathrm{~g})}, P_{g}\right)}\right. & =c^{\mathrm{CO}_{2(1)}}, \\
c^{\mathrm{OH}^{-}} & =K_{\mathrm{OH}^{-}} c^{\mathrm{H}^{+}}, \\
c^{\mathrm{HCO}_{3}^{-}} & =K_{\mathrm{HCO}_{3}-} c^{\mathrm{CO}_{2(1)}\left(c^{H^{+}}\right)^{-1},} \\
1 & =K_{\mathrm{CaCO}_{3}} c^{\mathrm{CO}_{2(1)}} c^{\mathrm{Ca}^{2+}}\left(c^{H^{+}}\right)^{-2} .
\end{aligned}
$$

In (14), for $\mathrm{CO}_{2(\mathrm{~g})}$ the activity $\gamma$ is a function of $c^{\mathrm{CO}_{2(\mathrm{~g})}}$ and the gas pressure $P_{g}$. For the aqueous species $\mathrm{OH}^{-}$and $\mathrm{HCO}_{3}{ }^{-}$, we use a model of ideal activity that considers activity equal to the concentration, and by convention the activity of water is taken to be equal to 1 . Finally, for $\mathrm{CaCO}_{3}$, the activity is taken as a constant and equal to 1 .

Now, we assume that in each phase, there exists a dominant species $\left(\mathrm{H}_{2} \mathrm{O}\right.$ in liquid phase and $\mathrm{CO}_{2(\mathrm{~g})}$ in gas phase) and that the other minor species do not affect much the flow. In this case:

$$
c_{d}=\left(\begin{array}{l}
c^{\mathrm{H}_{2} \mathrm{O}} \\
c^{\mathrm{CO}_{2(1)}} \\
c^{\mathrm{CO}_{2(\mathrm{~g})}}
\end{array}\right) \text { and } c_{m}=\left(\begin{array}{l}
c^{\mathrm{H}^{+}} \\
c^{\mathrm{Ca}^{2+}} \\
c^{\mathrm{OH}^{-}} \\
c^{\mathrm{HCO}_{3}^{-}} \\
c^{\mathrm{CaCO}_{3}}
\end{array}\right)
$$

Our strategy consists in solving sequentially:

- a simplified two-phase two-component flow system for $\mathrm{H}_{2} \mathrm{O}-\mathrm{CO}_{2}$ to compute pressures $P_{\alpha}$, velocities $\overrightarrow{q_{\alpha}}$, saturations $S_{\alpha}$ and the concentrations of the dominant species $c_{d}$,

- a reactive transport problem with these previously computed data to compute the concentrations of the minor species $c_{m}$. 
Consequently, the set of equations $(13,14)$ is split into two subsets. The first one is devoted to the two-phase two-component flow:

$$
\begin{aligned}
& \frac{\partial}{\partial t}\left(\theta_{l} c^{\mathrm{H}_{2} \mathrm{O}}\right)+L_{l}\left(c^{\mathrm{H}_{2} \mathrm{O}}\right)=\Psi_{1}\left(c^{\mathrm{OH}^{-}}, c^{\mathrm{HCO}_{3}{ }^{-}}, c^{\mathrm{CaCO}_{3}}\right), \\
& \frac{\partial}{\partial t}\left(\theta_{l} c^{\mathrm{CO}_{2(1)}}+\theta_{g} c^{\mathrm{CO}_{2(\mathrm{~g})}}\right)+L_{l}\left(c^{\mathrm{CO}_{2(1)}}\right)+L_{g}\left(c^{\mathrm{CO}_{2(\mathrm{~g})}}\right)=\Psi_{2}\left(c^{\mathrm{HCO}_{3}{ }^{-}}, c^{\mathrm{CaCO}_{3}}\right), \\
& \gamma\left(c^{\mathrm{CO}_{2(\mathrm{~g})}}, P_{g}\right)=c^{\mathrm{CO}_{2(1)}},
\end{aligned}
$$

with

$$
\Psi_{1}\left(c^{\mathrm{OH}^{-}}, c^{\mathrm{HCO}_{3}^{-}}, c^{\mathrm{CaCO}_{3}}\right)=-\frac{\partial}{\partial t}\left(\theta_{l}\left(c^{\mathrm{OH}^{-}}+c^{\mathrm{HCO}_{3}^{-}}\right)+c^{\mathrm{CaCO}_{3}}\right)-L_{l}\left(c^{\mathrm{OH}^{-}}+c^{\mathrm{HCO}_{3}^{-}}\right),
$$

and

$$
\Psi_{2}\left(c^{\mathrm{HCO}_{3}^{-}}, c^{\mathrm{CaCO}_{3}}\right)=-\frac{\partial}{\partial t}\left(\theta_{l} c^{\mathrm{HCO}_{3}^{-}}+c^{\mathrm{CaCO}_{3}}\right)-L_{l}\left(c^{\mathrm{HCO}_{3}^{-}}\right)
$$

The second subset is devoted to the reactive transport problem and is computed by solving the system:

$$
\begin{aligned}
& \frac{\partial}{\partial t}\left(\theta_{l} C_{l}^{\mathrm{H}^{+}}+C_{s}^{\mathrm{H}^{+}}\right)+L_{l}\left(C_{l}^{\mathrm{H}^{+}}\right)=0, \\
& \frac{\partial}{\partial t}\left(\theta_{l} C_{l}^{\mathrm{Ca}^{2+}}+C_{s}^{\mathrm{Ca}^{2+}}\right)+L_{l}\left(C_{\mathrm{Ca}^{2+}}\right)=0, \\
& c^{\mathrm{OH}^{-}}=K_{\mathrm{OH}^{-}} c^{\mathrm{H}^{+}}, \\
& c^{\mathrm{HCO}_{3}^{-}}=K_{\mathrm{HCO}_{3}^{-}} c^{\mathrm{CO}_{2(1)}\left(c^{H^{+}}\right)^{-1},} \\
& 1=K_{\mathrm{CaCO}_{3}} c^{\mathrm{CO}_{2(1)}} c^{\mathrm{Ca}^{2+}}\left(c^{H^{+}}\right)^{-2} .
\end{aligned}
$$

These two subsystems are solved sequentially. First, the computation of the two-phase two component flow is performed, with the contribution of the minor species (i.e. functions $\Psi_{1}$ and $\Psi_{2}$ ) treated explicitly, so as to uncouple the two steps. Then, the reactive transport problem is solved using quantities from the first step. Finally, concentrations of minor species $c_{m}$ are used to update the porosity (see eq. (10)) as well as the functions $\Psi_{1}$ and $\Psi_{2}$.

In the next section, we present our numerical methodology to solve our sequential approach.

\section{Numerical Simulation}

\subsection{Simulator}

Our methodology has been implemented in $\mathrm{DuMu}^{X}$ (DUNE for Multi-\{Phase, Component, Scale, Physics, ... $\}$ flow and transport in porous media) $[2,13]$, a free and open-source simulator for flow and transport processes in porous media, based on the Distributed and Unified Numerics Environment DUNE [3].

\subsubsection{Two-phase two-component flow}

For flow simulation, we have used a model already implemented in $\mathrm{DuMu}^{X}$. This model implements twophase two-component flow of two compressible and partially miscible fluids composed of two components. It is called $2 p 2 c$ (for two-phase two-component). The approach is fully implicit. The spatial discretization is performed by a vertex-centered finite volume approach while the time discretization is done by an implicit Euler scheme. The non-linear system is solved by a Newton method. 
In this model, the principal difficulty consists in taking into account the possible appearance and disappearance of a phase. This process is managed by a phase state dependent variable switch. Three different cases can be distinguished:

- Liquid and gas phases are present: liquid pressure $P_{l}$ and a saturation are used (either $S_{l}$ or $S_{g}$ ), as long as $0<S_{\alpha}<1$.

- Only liquid phase is present: liquid pressure $P_{l}$ and the mass fraction of $\mathrm{CO}_{2}$ in the liquid phase $X_{l}^{\mathrm{CO}_{2}}$ are used, as long as the maximum mass fraction is not exceeded $\left(X_{l}^{\mathrm{CO}_{2}}<X_{l, \max }^{\mathrm{CO}_{2}}\right)$.

- Only gas phase is present: liquid pressure $P_{l}$ and the mass fraction of $\mathrm{H}_{2} \mathrm{O}$ in the gas phase, $X_{g}^{\mathrm{H}_{2} \mathrm{O}}$ are used, as long as the maximum mass fraction is not exceeded $\left(X_{g}^{\mathrm{H}_{2} \mathrm{O}}<X_{g, \text { max }}^{\mathrm{H}_{2} \mathrm{O}}\right)$.

\subsubsection{Reactive transport}

For the reactive transport problem, we have first implemented in $\mathrm{DuMu}^{X}$ a one-phase multicomponent transport model. As starting point we used the single-phase, two-component model already implemented in $\mathrm{DuMu}^{X}$. This model implements a one-phase flow of a compressible fluid, that consists of two components. The primary variables are the pressure $p$ and the mole or mass fraction of dissolved components $x$. In our model, we want to impose the velocity and consequently the pressure. So, we have first removed the pressure from the set of primary variables. Then, we have increased the number of dissolved components from two to $N$. We have named this new model $1 p N c$ for one-phase $\mathrm{N}$-component.

The last component is a locally developed code for chemical equilibrium called ChemEqLib [1,5]. This code solves the chemical equilibrium problem that consists of mass actions laws and mass conservation laws. The proposed formulation can involve both homogeneous (aqueous complexation) and heterogeneous reactions (mineral dissolution/precipitation and ion exchange). For minerals, one does not know a priori which species are in the solid form, and which are dissolved, leading to a system of equations that is of complementarity type. In the ChemEqLib code, this is handled by an outer loop over the possibly dissolved mineral species, and a check as to whether the included species are not over- or under-saturated (see [6]). At each of these outer iteration, a non-linear system is solved using a globally convergent Powell's hybrid method.

To solve the reactive transport subsystem, we have coupled the $1 p N c$ and ChemEqLib codes. The reactive transport problem can be written as follows:

$$
\begin{aligned}
\frac{\partial\left(\phi S_{l} C_{l}\right)}{\partial t}+\frac{\partial C_{s}}{\partial t}+L_{l}\left(C_{l}\right) & =0 \\
T & =\phi S_{l} C_{l}+C_{s}, \\
C_{s} & =\Psi_{C}(T),
\end{aligned}
$$

where $C_{l}$ is the vector of the total concentration of liquid species while $C_{s}$ is the vector of the total concentration of solid species. Equation (16) corresponds to the resolution of the chemical equilibrium. In the literature, many approaches have been proposed to solve reactive transport problem. Sequential approaches (see for instance [10,30]) consists in solving sequentially the transport and chemical reactions. In the direct substitution approaches, the equation of chemistry are directly substituted in the equations of transport. This can be done explicitly as in [14] or implicitly as in $[19,23]$ or [4]. The problem can also be reformulated as a differential algebraic system (DAE) as in [11].

A benchmark for comparing numerical methods for reactive transport was proposed in [9], with several groups assessing the performance of the various methods on a common problem, devised to be representative of actual field studies. The results are synthesized in the overview article [8], and show that the sequential iterative approach can be made as accurate as the fully coupled one (and also that the fully coupled approach can be implemented efficiently). Consequently, in this work, we have used a sequential iterative approach (SIA) as described in $[10,30]$. 
Supposing $C_{l}^{n}, C_{l}^{n+1, k}, C_{s}^{n}, C_{s}^{n+1, k}, S_{l}^{n+1}, S_{l}^{n}, \phi^{n}$ are known, $T^{n+1, k+1}, C_{s}^{n+1, k+1}, C_{l}^{n+1, k+1}$ are computed thanks to the following iterative scheme:

$$
\begin{gathered}
\phi^{n} \frac{S_{l}^{n+1} C_{l}^{n+1, k+1}-S_{l}^{n} C_{l}^{n}}{\Delta t}+\frac{C_{s}^{n+1, k}-C_{s}^{n}}{\Delta t}+L_{l}\left(C_{l}^{n+1, k+1}\right)=0 \\
T^{n+1, k+1}=\phi^{n} S_{l}^{n+1} C_{l}^{n+1, k+1}+C_{s}^{n+1, k} \\
C_{s}^{n+1, k+1}=\Psi_{C}\left(T^{n+1, k+1}\right) .
\end{gathered}
$$

where $\phi^{n}$ is an approximation of the porosity computed at time $n \Delta t, S_{l}^{n+1}$ and $S^{n}$ denote approximations of the saturations respectively at time $(n+1) \Delta t$ and $n \Delta t$. For the other quantities we used the following convention: $C_{l}^{n, k}$ denotes the approximation of quantity $C_{l}$ at time $n \Delta t$ and at iteration $k$ in the iterative loop of the SIA algorithm.

The algorithm is stopped when:

$$
\frac{\left\|C_{l}^{n+1, k+1}-C_{l}^{n+1, k}\right\|}{\left\|C_{l}^{n+1, k+1}\right\|}+\frac{\left\|C_{s}^{n+1, k+1}-C_{s}^{n+1, k}\right\|}{\left\|C_{s}^{n+1, k+1}\right\|}<\epsilon,
$$

where $\|$.$\| is a discrete L^{2}$ norm, and $\epsilon$ is a given tolerance $(\epsilon \ll 1)$.

Note that all terms coming from the flow subsystem are treated explicitly. Even though $S_{l}^{n+1}$ appears, this is a known quantity that has been computed in the flow stage. The same applies for the term $\phi^{n}$ : we do not re-evaluate the porosity during the reactive transport step.

\subsection{Application Example}

To validate our methodology, we have carried out a test introduced by Saaltink et al. in [25]. The authors of this article elaborate a coupled physical model of two-phase multicomponent flow and construct a numerical simulator that solves the entire system using a fully-coupled approach. To reduce the complexity of the considered numerical task, the authors chose a simplified method for computing chemical equilibrium states, whereas in our case the full nonlinear system for equilibrium is solved. Instead of solving a system of mass action laws coupled with expression of total concentrations (section 1.1), the authors of [25] use a pre-calculated tabulated function that returns the concentrations of all species at chemical equilibrium according to the value of gas pressure. This choice simplifies the computation and reduces computing time. However, it created a difficulty for reproducing the test conditions. The functions for important chemical species are presented as graphs (see Figure 1 in [25]). For convenience, we have reproduced this illustration in Figure 2.

\subsubsection{Definition of the test}

The domain is an axisymmetric 2D geometry of $100 \mathrm{~m}$ thickness, representing a horizontal aquifer at $1500 \mathrm{~m}$ depth. The domain extends to $5 \mathrm{~km}$ laterally and an injection well with a radius of $0.15 \mathrm{~m}$ is located at the centre of the domain.

The chemical system coincides with the one introduced in table 1. Temperature of the reservoir is constant and equal to $T=333 \mathrm{~K}$. The equilibrium constants for the reactions are shown in table 2 . As previously mentioned, the values were computed from the graphs of primary species concentration in Figure 2, and for this reason can slightly differ from the values actually used in [25].

Constitutive laws and physical parameters are given in table 3. Initial porosity is equal to 0.1.

As initial conditions for the two-phase two-component $\mathrm{H}_{2} \mathrm{O}-\mathrm{CO}_{2}$ flow we have used hydrostatic condition for liquid pressure $P_{l}$, initial liquid saturation $S_{l}=1$ and initial $\mathrm{CO}_{2}$ concentration in liquid phase equals $1.22310^{-4}$ mol. $1^{-1}$. Initial conditions for the reactive transport problem are shown in table 4. Because in the article [25], the concentrations of chemical species are computed as explicit functions of the gas pressure no initial values are needed. In our model, the concentrations of primary species are system variables, and we need to know 

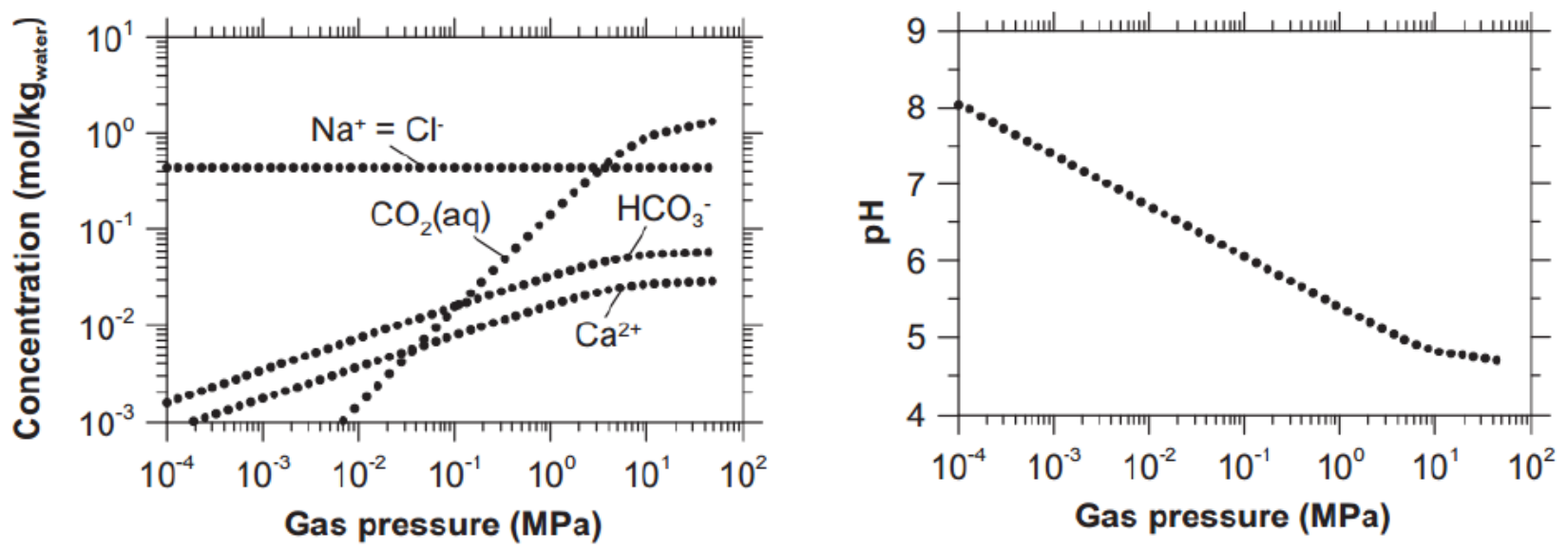

Figure 2. Concentrations of the most important chemical species $\left(\mathrm{CO}_{2(1)}, \mathrm{HCO}_{3}^{-}, \mathrm{Ca}^{2+}, \mathrm{Cl}^{-}\right)$ and $\mathrm{pH}$ as a function of gas pressure. Taken from [25].

\begin{tabular}{|l|lllll|}
\hline & $\mathrm{H}_{2} \mathrm{O}$ & $\mathrm{H}^{+}$ & $\mathrm{CO}_{2(1)}$ & $\mathrm{Ca}^{2+}$ & $\log K$ \\
\hline $\mathrm{OH}^{-}$ & 1 & -1 & 0 & 0 & -14 \\
$\mathrm{HCO}_{3}{ }^{-}$ & 1 & -1 & 1 & 0 & -5.928 \\
$\mathrm{CaCO}_{3}$ & 1 & -2 & 1 & 1 & -8.094 \\
\hline Total & $T_{\mathrm{H}_{2} \mathrm{O}}$ & $T_{\mathrm{H}^{+}}$ & $T_{\mathrm{CO}_{2(1)}}$ & $T_{\mathrm{Ca}^{2+}}$ & \\
\hline
\end{tabular}

TABLE 2. Morel's table.

their values at initial time. Consequently, these values were read off the graph in Figure 2 with an initial gas pressure equal to $10^{-3} \mathrm{MPa}$.

An additional difficulty caused by the choice of a sequential procedure is that we need to prescribe separate boundary conditions for the two sub-problems. For the two-phase two-component $\mathrm{H}_{2} \mathrm{O}-\mathrm{CO}_{2}$ flow, a prescribed $\mathrm{CO}_{2}$ mass flow rate (2.5 Mt.year $\left.{ }^{-1}\right)$ is imposed at the injection well, no flow conditions are imposed at the upper and lower parts of the domain and finally, a constant pressure is enforced at the outer boundary. For the reactive transport problem, a Dirichlet boundary condition equal to the initial condition is imposed for the concentrations, impermeable Neumann boundary conditions are enforced at the upper and lower parts of the domain and an outflow boundary condition is applied at the outlet.

\subsubsection{Numerical results}

The period of simulation is equal to 1 year. In [25], the authors used a two-dimensional mesh containing 6600 elements. The size of the elements is $5 m$ close to the injection well while it increases up to $30 m$ close to the outer boundary. It is impossible for us to deal with the same mesh so we have used a mesh with a constant step size equal to the finest size in [25], that is $5 \mathrm{~m}$. Our corresponding mesh contains 10000 elements $(500 \times 20)$. For the time step management, $\mathrm{DuMu}^{X}$ adapts automatically the time step according to the number of iterations needed in the Newton scheme to solve the non-linear problem. For this test case, we fixed the maximal time step equal to 1 day. This choice will be justified in section 3.2.3.

Figure 3 exhibits the liquid saturation after 100 days and 1 year of $\mathrm{CO}_{2}$ injection. The gas migrates upward by buoyancy effect until it reaches the top of the domain with no flux conditions and then it is driven to the right by advective forces and almost completely displaces the liquid phase in the zone of gas phase presence. Comparing our results with those of Saaltink et al. [25], we observe that the form and the velocity of the gas phase plume in both simulation show no significant differences. 


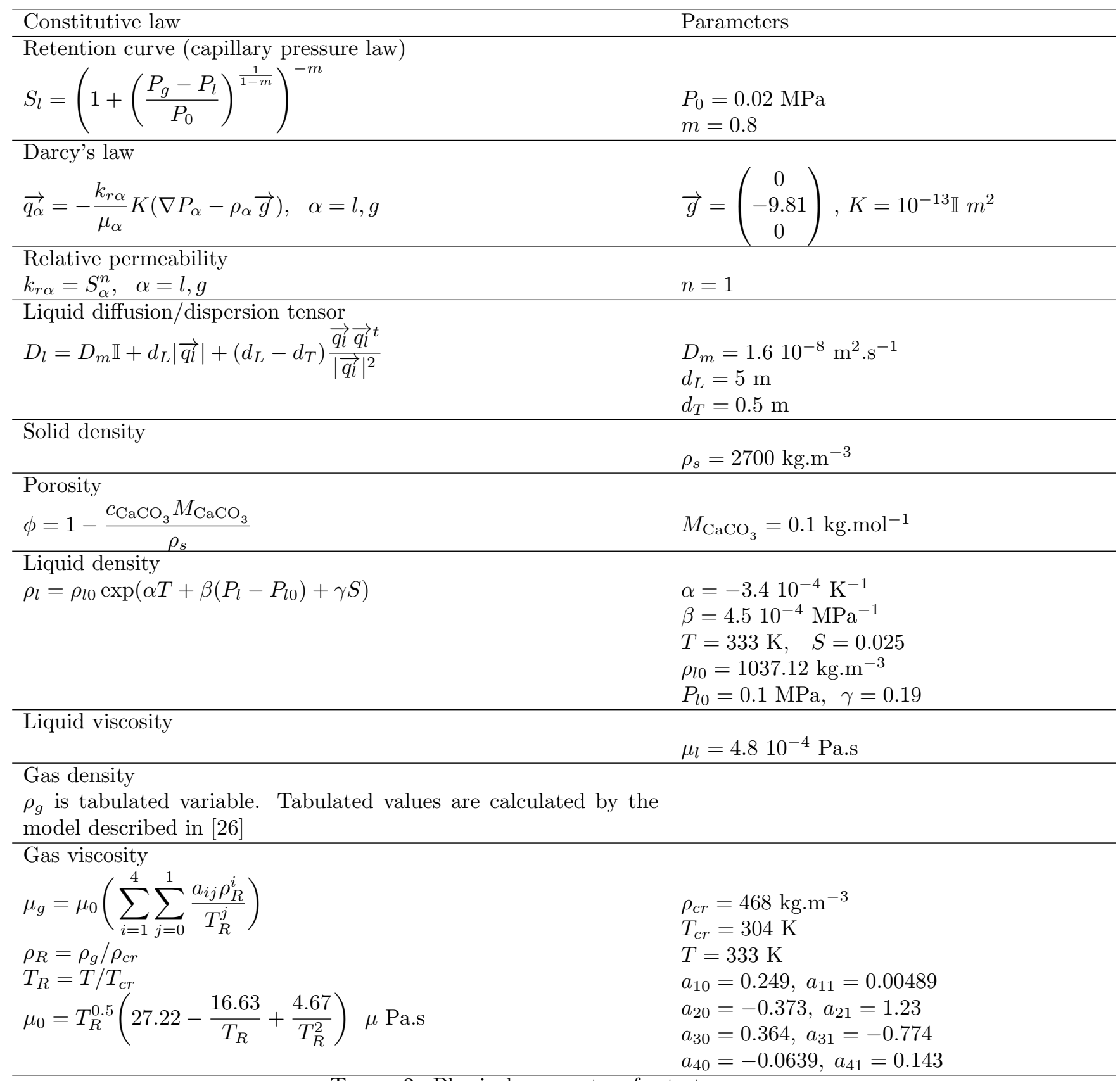

TABLE 3. Physical parameters for test case.

Figure 4 shows the gas pressure after 100 days and 1 year of $\mathrm{CO}_{2}$ injection. The evolution of the gas pressure is strongly coupled with the evolution of gas phase. The gas pressure reaches its highest value on the left boundary because of the continuous process of $\mathrm{CO}_{2}$ injection. As it approaches the boundary of the gas plume, the gas pressure is slowly decreasing. In the zone without gas phase presence we assume that gas pressure is zero. Comparing our results with those obtained by Saaltink et al. [25], we observe that the general picture 


\begin{tabular}{|lcccc|}
\hline & conc. & total conc. & total liquid conc. & total solid conc. \\
\hline $\mathrm{H}^{+}$ & $4.08110^{-8}$ & -48.6 & $-3.50310^{-3}$ & -48.6 \\
$\mathrm{Ca}^{2+}$ & $1.70810^{-3}$ & 24.3 & $1.70810^{-3}$ & 24.3 \\
\hline
\end{tabular}

TABLE 4. Initial conditions for reactive transport problem (in mol. $1^{-1}$ ).

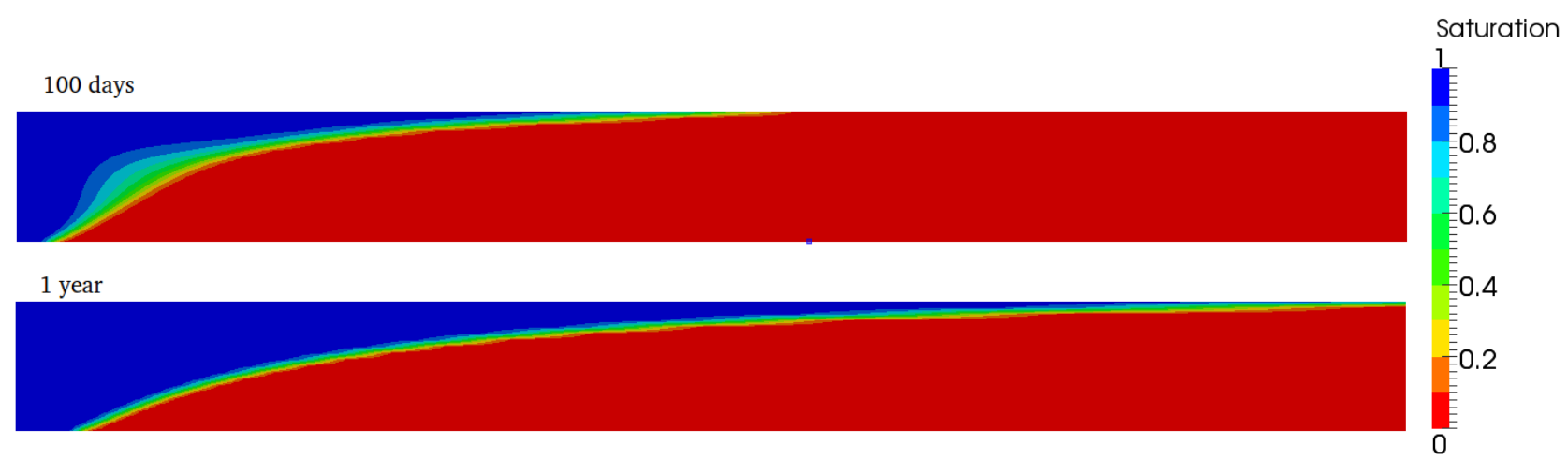

Figure 3. Liquid saturation $S_{l}$ after 100 days and 1 year of $\mathrm{CO}_{2}$ injection. Only the $1.1 \mathrm{~km}$ closest to the injection is presented.

of the gas pressure evolution coincide, but the computed maximum values are different (a difference of $6.5 \%$ is observed). A possible explanation is the difference between the models used in both simulation. For instance in [25], the effects of dissolution of calcite are taken into account to change the porosity and the permeability while in our case, only the porosity is modified and the permeability remains constant.

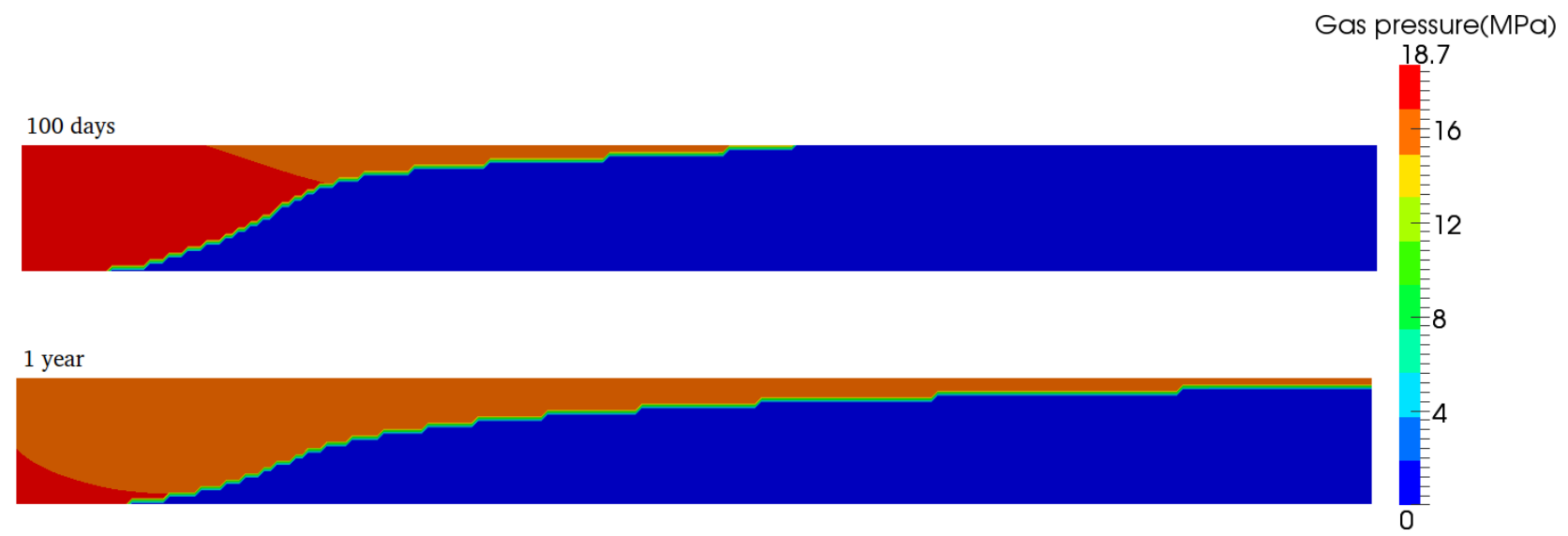

Figure 4. Gas pressure $P_{g}$ after 100 days and 1 year of $\mathrm{CO}_{2}$ injection. Only the $1.1 \mathrm{~km}$ closest to the injection is presented.

The distribution of the liquid density, represented in Figure 5, is strongly coupled with the distribution of gas pressure because an increase in gas pressure causes an increase in the amount of dissolved $\mathrm{CO}_{2}$ that in turn causes an increase in liquid phase density. At the same time, we observe that the region containing dissolved $\mathrm{CO}_{2}$ is larger than the gaseous $\mathrm{CO}_{2}$, especially in the lower left part of the domain. This is caused by the 
vertical dispersion of the liquid $\mathrm{CO}_{2}$ and by a vertical downward flux due to denser $\mathrm{CO}_{2}$ saturated liquid phase being on top of a lighter non-saturated zone.

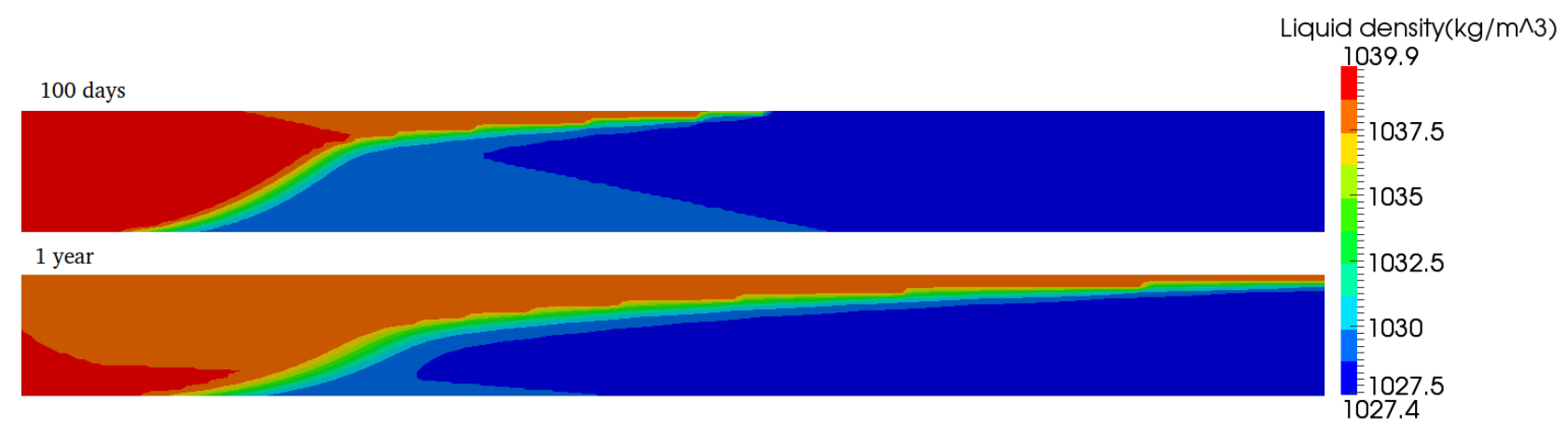

FIgURE 5. Liquid density $\rho_{l}$ after 100 days and 1 year of $\mathrm{CO}_{2}$ injection. Only the $1.1 \mathrm{~km}$ closest to the injection is presented.

Figure 6 represents the precipitation/dissolution of calcite after 100 days of injection of $\mathrm{CO}_{2}$. In the vicinity of $\mathrm{CO}_{2}$, the calcite is dissolved. Calcite dissolves in zones where the liquid phase contains dissolved carbon dioxide reacting with mineral calcite. The amount of dissolved calcite is maximal close to the injection border and gradually decreases as the boundary of the liquid $\mathrm{CO}_{2}$ plume is approached. Although the same trend is observed in both simulations, the actual amount of dissolved calcite inside of gaseous $\mathrm{CO}_{2}$ differs from that obtained in [25]. To better see the difference we give a more precise comparison of the simulations in Figure 7, by showing a graph of precipitated/dissolved calcite volume fraction after 100 days of $\mathrm{CO}_{2}$ injection at two depths as a function of distance from the left side of the domain. We observe that the quantity of dissolved calcite decreases with the distance to the left border. The shapes of both graphs obtained in our simulation and from the results of [25] are similar, but the actual values are different. This difference can be explained by the possibly different values of the equilibrium constants, as noted in section 3.2.1.

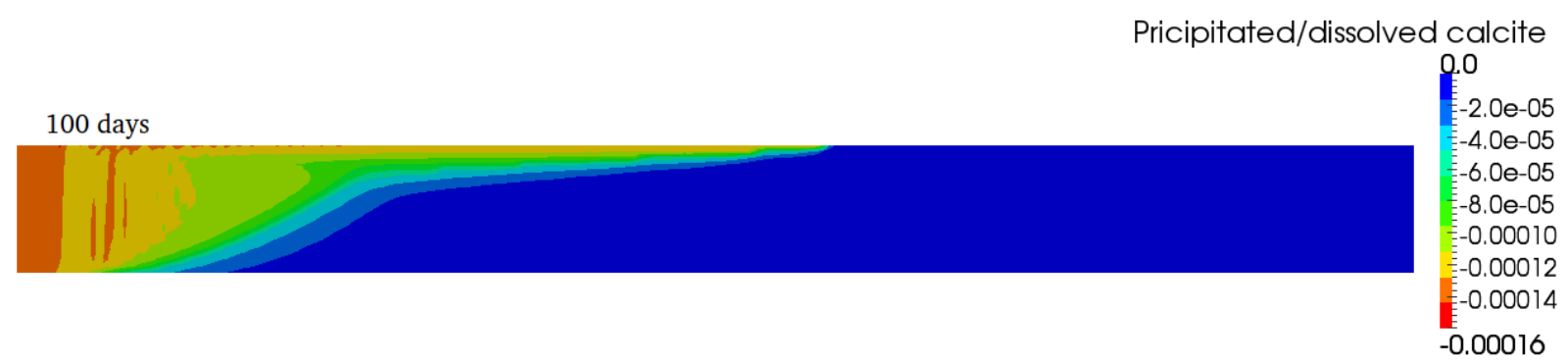

Figure 6. Precipitated/dissolved calcite volume fraction after 100 days of $\mathrm{CO}_{2}$ injection. Only the $1.1 \mathrm{~km}$ closest to the injection is presented.

Figures 8 and 9 display respectively the temporal evolution of gas pressure and liquid density obtained in ours and Saaltink et al.'s simulations at 2 different locations. During the initial period, the gas phase is not present and the gas pressure at both locations is equal to zero. At the same time liquid density slightly increases under the influence of the rising pressure in the liquid phase. When the gas phase appears at the considered point, the gas pressure increases to its maximum value. The gas dissolves in the liquid phase and causes a large jump in liquid density. During the rest of the simulation the gas pressure slowly decreases. A similar change in liquid pressure leads to the slight decreasing of liquid pressure. A qualitatively similar evolution is observed in both results, but the gas phase appears earlier in our results. A possible explanation may be that the simulators used in both cases have not exactly the same strategy for the management of phase appearance/disappearance. 

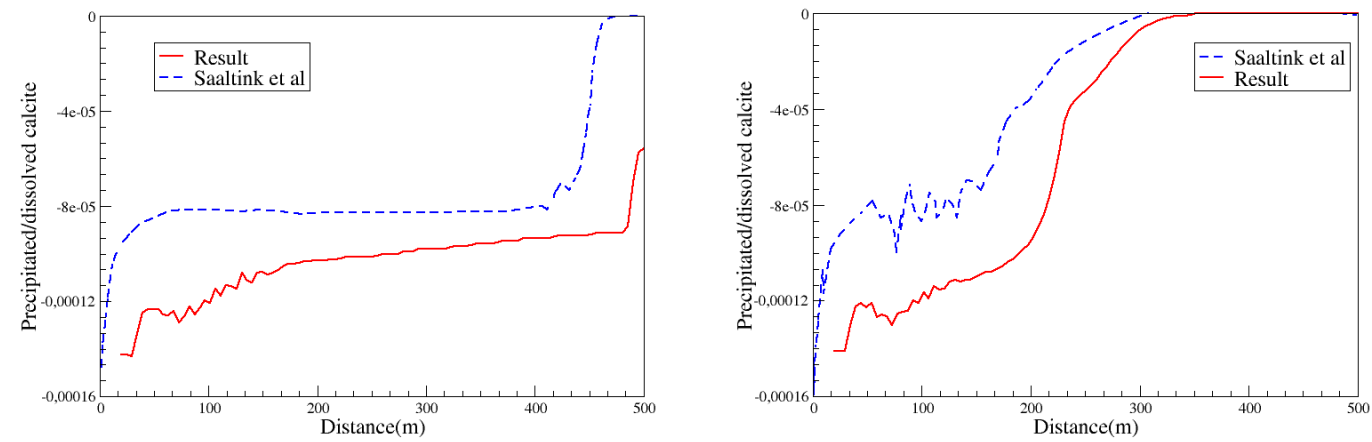

Figure 7. Precipitated/dissolved calcite volume fraction after 100 days of $\mathrm{CO}_{2}$ injection at two depths (depth equals $10 \mathrm{~m}$ on the left and $50 \mathrm{~m}$ on the right). Red lines represent obtained results. Blue lines represent M. W. Saaltink's results. Dissolution is indicated by negative values.

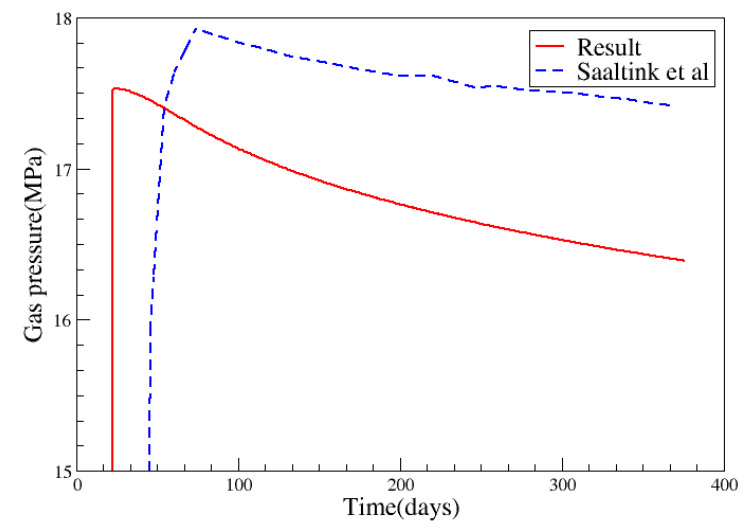

Figure 8. Gas pressure evolution at a point placed $200 \mathrm{~m}$ away from the injection well and $25 \mathrm{~m}$ below the top of the aquifer. Red line represents obtained results. Blue line represents M. W. Saaltink's results.

\subsubsection{Convergence analysis}

To check the convergence of the solution in time, we have compared in figure 10 the precipitation/dissolution of calcite after 100 days of injection of $\mathrm{CO}_{2}$, for different time steps (12 hours, 1 day and 2 days) with a mesh composed of 10000 elements. We can see that results are very close and it is for this reason that we used a time step equal to one day in section 3.2.2.

To check convergence of the solution in space, we have computed four parameters characterizing the flow :

- the maximal gas pressure $P_{g}^{\max }$,

- the maximal liquid pressure $P_{l}^{\max }$,

- the maximal gas density $\rho_{g}^{\max }$,

- the maximal liquid density $\rho_{l}^{\max }$. 


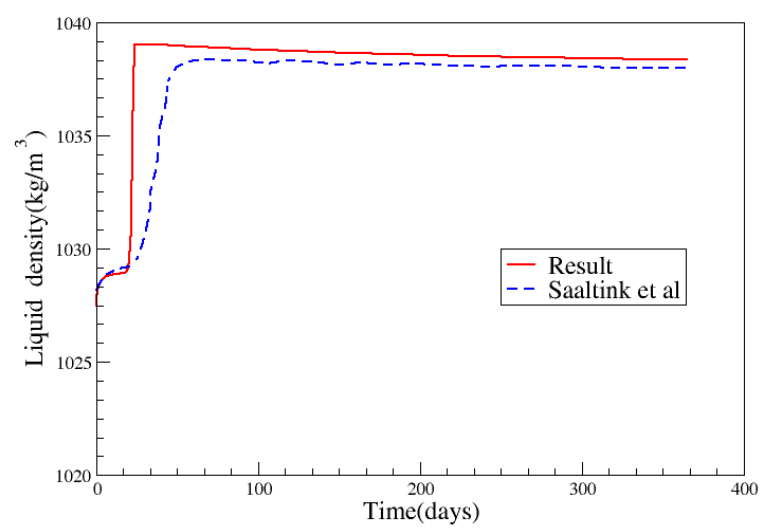

FIgURE 9. Liquid density evolution at a point placed $200 \mathrm{~m}$ away from the injection well and $25 \mathrm{~m}$ below the top of the aquifer. Red line represents obtained results. Blue line represents M. W. Saaltink's results.

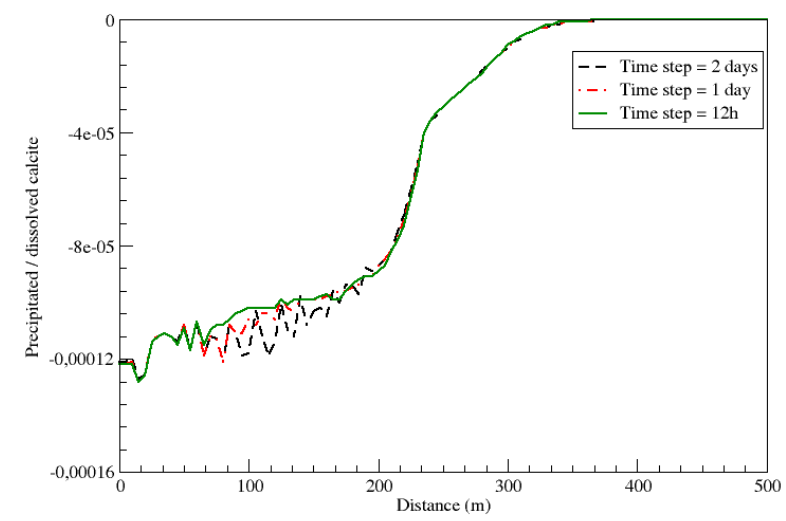

Figure 10. Comparison of precipitated/dissolved calcite volume fraction after 100 days of $\mathrm{CO}_{2}$ injection as a function of the time step.

The Richardson extrapolation framework $[7,22]$ is used to compute the convergence rates and extrapolated values of these parameters computed on three meshes with step size $h_{1}, h_{2}$ and $h_{3}$, such that two consecutive ratio are equal to two. The convergence rate $p$ and the extrapolated value $f_{\text {ext }}$ are given by the well known formulas:

$$
p=\frac{\log \left(\frac{f_{3}-f_{2}}{f_{2}-f_{1}}\right)}{\log \left(\frac{h_{2}}{h_{1}}\right)}, \quad f_{\text {ext }}=\frac{f_{2}-f_{1}\left(\frac{h_{2}}{h_{1}}\right)^{p}}{1-\left(\frac{h_{2}}{h_{1}}\right)^{p}} .
$$

The results are detailed in table 5 . One can see that a first order space convergence rate is obtained. 


\begin{tabular}{|l|lllll|}
\hline Space step size & 10 & 5 & 2.5 & \multicolumn{2}{l|}{ Extrapolation } \\
\cline { 4 - 6 } & & & & Value & Order \\
\hline$P_{g}^{\max }(\mathrm{MPa})$ & 17.628 & 16.988 & 16.678 & 16.387 & 1.046 \\
$P_{l}^{\max }(\mathrm{MPa})$ & 17.549 & 16.909 & 16.599 & 16.307 & 1.045 \\
$\rho_{g}^{\max }\left(\mathrm{kg} \cdot \mathrm{m}^{-3}\right)$ & 679.23 & 664.26 & 656.41 & 647.75 & 0.931 \\
$\rho_{l}^{\max }\left(\mathrm{kg} \cdot \mathrm{m}^{-3}\right)$ & 1039.2 & 1038.8 & 1038.6 & 1038.4 & 0.925 \\
\hline
\end{tabular}

TABLE 5. Convergence rates and extrapolated values for characteristic flow parameters, after 100 days of injection.

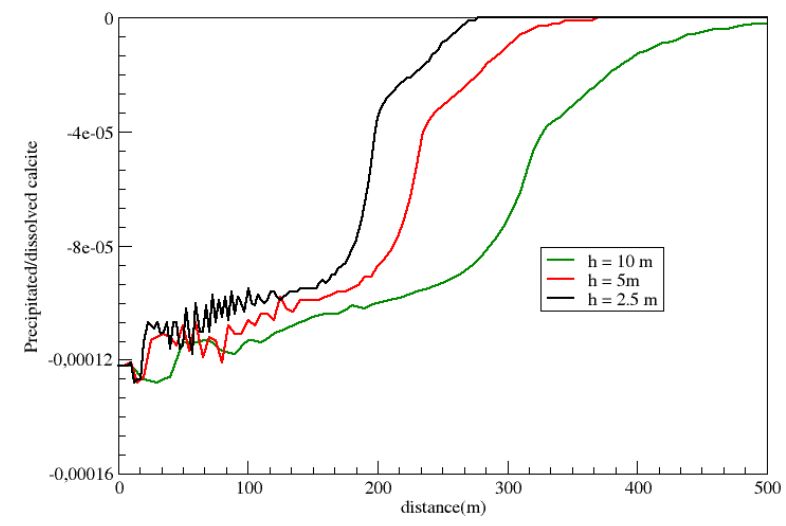

FIGURE 11. Comparasion of precipitated/dissolved calcite volume fraction after 100 days of $\mathrm{CO}_{2}$ injection for differents meshes.

Figure 11 compares the precipitation/dissolution of calcite after 100 days of injection of $\mathrm{CO}_{2}$ for three different meshes corresponding to the results exhibited in table 5. The oscillations seen of the finest mesh cannot be seen on the coarsest mesh. Their origin is actually due to the time step, but their amplitude depends on the spatial mesh size.

Finally, we note that, for the two-phase two-component flow subsystem, the Newton solver takes an average of 10 iterations. In the reactive transport subsystem, the sequential iterative algorithm takes an average of 7 iterations with a tolerance equal to $10^{-7}$.

\section{CONCLUSION}

In this article, we have proposed a method for the simulation of two-phase multicomponent flow with reactive transport by coupling existing simulators for (compositional) two-phase flow, transport and geochemistry. The method is based on a sequential approach. We have carefully described the different steps, as well as the coupling method itself, and have validated the approach on a representative example from the literature. Though the example used a two-dimensional geometry, it is clear that our approach can be extended to 3D geometries with very little modifications to the existing code. Indeed, The use of an existing and well established framework such as $\mathrm{DuMu}^{X}$ to implement the simulations has presented several advantages. First, the framework provided most of the basic numerical tools for implementing the new methods. Then, the structure of the framework means that extensions to quite varied geometrical and physical situations will be reasonably straightforward. Consequently, work is currently under way to apply the method to a 3D example, more representative of actual 
$\mathrm{CO}_{2}$ storage situations. This will require the development of a parallel implementation of the method $\left(\mathrm{DuMu} \mathrm{u}^{\mathrm{X}}\right.$ itself already runs in parallel, but the difficulty comes from devising a load balancing strategy that would be valid both for flow and for chemistry).

Acknowledgement This work was carried out as part of the $\mathrm{PhD}$ thesis of $\mathrm{V}$. V. The thesis was supervised by Brahim Amaziane. The authors thank Prof. Amaziane for his support and his useful advice.

\section{REFERENCES}

[1] ChemEqLib: a chemical equilibrium library. webpage: https://gforge.inria.fr/projects/chemeqlib.

[2] DuMux, DUNE for multi-Phase, Component, Scale, Physics, ... flow and transport in porous media. web-page: http://www.dumux.org.

[3] DUNE, the distributed and unified numerics environment. web-page: http://www.dune-project.org.

[4] L. Amir and M. Kern. A global method for coupling transport with chemistry in heterogeneous porous media. Computational Geosciences, 14:465-481, 2009.

[5] J-B. Apoung, P. Havé, J. Houot, M. Kern, and A. Semin. Reactive transport in porous media. ESAIM: Proc., 28:227-245, 2009.

[6] C. M. Betke. Geochemical reaction modeling. Concepts and applications. Oxford University Press, 1996.

[7] C. Brezinksi and M. Redivo Zaglia. Extrapolation Methods. Theory and Practice. Amsterdam, North-Holland Albuquerque, 1991.

[8] J. Carrayrou, J. Hoffmann, P. Knabner, S. Kräutle, C. de Dieuleveult, J. Erhel, J. Van der Lee, V. Lagneau, K.U. Mayer, and K.T.B MacQuarrie. Comparison of numerical methods for simulating strongly nonlinear and heterogeneous reactive transport problems - the MoMaS benchmark case. Computational Geosciences, 14(3):483-502, 2010.

[9] J. Carrayrou, M. Kern, and P. Knabner. Reactive transport benchmark of MoMaS. Computational Geosciences, 14(3):385-392, 2010.

[10] J. Carrayrou, R. Mosé, and P. Behra. Operator-splitting procedures for reactive transport and comparison of mass balance errors. J. Contam. Hydrol, 68:239-268, 2004.

[11] C. de Dieuleveult, J. Erhel, and M. Kern. A global strategy for solving reactive transport equations. J. Comput. Phys, 228:6395-6410, 2009.

[12] Y. Fan, L.J. Durlofsky, and H.A. Tchelepi. A fully-coupled flow-reactive-transport formulation based on element conservation, with application to $\mathrm{CO}_{2}$ storage simulations. Advances in Water Resources, 42:47-61, 2012.

[13] B. Flemisch, M. Darcis, K. Erbertseder, B. Faigle, A. Lauser, K. Mosthaf, S. Muthing S., P. Nuske, A. Tatomir, M. Wolf, and R. Helmig. DuMu ${ }^{X}$ : Dune for multi-\{Phase, Component, Scale, Physics, ...\} flow and transport in porous media. Advances in Water Resources, 34(9):1102-1112, 2011.

[14] G. E. Hammond, A. Valocchi, and P. Lichtner. Application of Jacobian-free Newton-Krylov with physics-based preconditioning to biogeochemical transport. Advances in Water Resources, 28:359-378, 2005.

[15] G.E. Hammond, P.C. Lichtner, C. Lu, and R.T. Mills. PFLOTRAN: Reactive flow 8 transport code for use on laptops to leadership-class supercomputers, pages 141-159. In Zhang et al. [31], 2012.

[16] Y. Hao, Y. Sun, and J.J. Nitao. Overview of NUFT: A versatile numerical model for simulating flow and reactive transport in porous media, pages 212-239. In Zhang et al. [31], 2012.

[17] R. Helmig. Multiphase Flow and Transport Processes in the Subsurface: A Contribution to the Modeling of Hydrosystems. Springer, 1997.

[18] X. Jiang. A review of physical modelling and numerical simulation of long-term geological storage of $\mathrm{CO}_{2}$. Applied energy, 88:3557-3566, 2011.

[19] S. Kräutle and P. Knabner. A reduction scheme for coupled multicomponent transport-reaction problems in porous media: Generalization to problems with heterogeneous equilibrium reactions. Water Resources Research, 43, 2007.

[20] F.M.M. Morel and J.G. Hering. Principles and Applications of Aquatic Chemistry. Wiley, New York, 1993.

[21] Intergovernmental Panel on Climate Change (IPCC). IPCC special report on carbon dioxide capture and storage. In B. Metz, O. Davidson, H.C. de Coninck, M. Loos, and L.A. Meyer, editors, IPCC Special Report on Carbon Dioxide Capture and Storage. Cambridge University Press, 2005. Prepared by Working Group III of the Intergovernmental Panel on Climate Change.

[22] P.J. Roache. Verification and validation in computational science and engineering. Albuquerque: Hermosa Publishers, 1998.

[23] M. Saaltink, C. Ayora, and J. Carrera. A mathematical formulation for reactive transport that eliminates mineral concentrations. Water Resources Research, 34:1649-1656, 1998.

[24] M. Saaltink, F. Batlle, C. Ayora, J. Carrera, and J. Olivella. Retraso, a code for modeling reactive transport in saturated and unsaturated porous media. Geologica Acta, 2, 2004.

[25] M. Saaltink, V. Vilarrasa, F. De Gaspari, O. Silva, J. Carrera, and T.S. Rötting. A method for incorporating equilibrium chemical reactions into multiphase flow models for co2 storage. Advances in Water Resources, 62:431-441, 2013. 
[26] R. Span and W. Wagner. A new equation of state for carbon dioxide covering the fluid region from the triple-point temperature to $1100 \mathrm{~K}$ at pressures up to $800 \mathrm{MPa}$. J. Phys. Chem. Data, 1996.

[27] M.F. Wheeler, S. Sun, and S.G. Thomas. Modeling of flow and reactive transport in IPARS, pages 42-73. In Zhang et al. [31], 2012.

[28] T. Xu and K. Pruess. Coupled modeling of non-isothermal multi-phase flow, solute transport and reactive chemistry in porous and fractured media: 1. model development and validation. Journal of Geophysical Research, 1998.

[29] T. Xu, E. Sonnenthal, N. Spycher, G. Zhang, L. Zheng, and K. Pruess. Toughreact: A simulation program for subsurface reactive chemical transport under non-isothermal multiphase flow conditions, pages 74-95. In Zhang et al. [31], 2012.

[30] G.T. Yeh and V.S. Tripathi. A critical evaluation of recent developments in hydrogeochemical transport models of reactive multi-chemical components. Water Resources Research, 25:93-108, 1989.

[31] F. Zhang, G.T. Yeh, and J.C. Parker, editors. Groundwater Reative transport models. Bentham e-books, 2012. 